\title{
EDITORIAL METHOD
}

This is a classed catalog. The contents of 700 vocal manuscripts are inventoried; all date before the year 1900 , except item 699 . The entries are arranged sequentially by a catalog item number, 1 through 700 , assigned by the compiler, not by acquisition number order or by shelf number order. The manuscripts are systematically grouped into six broad categories. This classification seemed to provide the most logical organization for this particular collection:

1. Items 1-445 are manuscripts with music by a single identified composer. The items are arranged alphabetically by the last name of the composer.

2. Items 446-526 are manuscripts with music by a single anonymous composer. These items are subdivided by language: Italian (446-84), Latin (485-519), Other (520-26).

3. Items 527-627 are collections (anthologies) containing musical compositions by more than one composer. These are also subdivided by language: Italian (527-609), French (610-21), English (622-25), and German (626-27).

4. Items 628-47 are collections of religious compositions and Service music in Latin (628-41) and English (642-47).

5. Items 648-90 are Gregorian chant books and fragments.

6. Items 691-700 include music treatises, an anthology of vaudevilles in French without music, and a collection of correspondence related to another manuscript.

Access to specific information is available by means of 11 indexes appended to the end of the catalog. These indexes consist of: (1) personal names (composers, performers, owners, copyists, etc.); (2) titles of dramatic works; (3) song titles and first lines; (4) musical genres; (5) names of cities; (6) names of theaters; (7) names of dramatic characters; (8) names of liturgical feasts; (9) dates that occur in the manuscripts; (10) watermarks; and (11) a concordance table that permits the identification of a manuscript from its shelf number.

Whenever applicable, each entry contains bibliographical information that is presented in a fixed order:

1. Catalog item number and the manuscript shelf number

2. Composers (and other proper names) 
3. Title

4. Physical collation

5. Provenance and date

6. Inscription

7. Remarks

8. Inventory of contents

9. Bibliographical reference(s)

\section{Manuscript Shelf Numbers}

A manuscript signature consisting of Arabic numbers only denotes a single volume, for example:

Item 596 (MS 118). Collection of 45 Italian canzoni.

In contrast, a signature that is followed by lower-case letters indicates the presence of several independent, but constituent bibliographical nuembers of the manuscript. For example, item 199 consists of 13 separate partbooks; these are indicated by the letters "a-m":

Item 199 (MS 945 a-m). Eberlin, Johann Ernst, 1702-62. Passion oratorio “Heu me! Quam spissae tenebrae."

Among libraries there is some imprecision concerning the definition of what constitutes "a manuscript." For statistical purposes, more than anything else, it is possible to inflate overall counts by assigning several manuscript numbers to a single physical volume. For example, Item 592 (MS 1081) is a factitious collection of Italian music bound into one volume of 327 folios. It manifests many scribal hands, several varieties and sizes of paper, and an assemblage of gatherings that date from 1784 to 1832 . Some libraries might assign multiple manuscript numbers to such an anthology; at Berkeley, however, it is counted as one manuscript.

\section{Composers and Other Proper Names}

The spelling of proper names, such as composers, performers, librettists, owners, etc., adheres to forms used in The New Grove Dictionary (1980), the most recent and definitive music encyclopedia. Likewise, it is the preferred source for birth and death dates. Whenever The New Grove Dictionary proved insufficient, other standard reference works were consulted. The exact form of a proper name as it appears in the manuscript will be found under the Inscription. Problems relating to attribution are usually discussed under Remarks. As a convenience to the reader, the dates of composers and singers (when known) are repeated in each of the collection descriptions (items 527-627).

Title

Manuscripts, unlike printed books, lack uniform title-page inscriptions. Some manuscript titles exude rich information: subtitles, dates, places, dedications, and names of performers, owners, theaters, etc.; in others, this information is sparse, misleading, or absent.

These unpredictable circumstances affect the form of the title entries used in this catalog. In general there are two types. In the first category, the title entry is established 
directly from the manuscript inscription and/or the text incipit; additional explanatory information, such as the date of the first performance of an opera that establishes a reliable terminus a quo for the composition, is given as seems appropriate, for example:

Aria "Vanne a morte, o figlio mio" (C) [from Giunio Bruto (1781)] [from item 167]

The second type of title entry is a succinct descriptive statement devised by the compiler that summarizes fundamental bibliographical aspects of the manuscript. Ordinarily these titles apply to collections containing mixed genres of music and to manuscripts lacking inscriptions entirely, for example:

Collection of 14 arias, 1 duet, 5 miscellaneous songs, in Italian, and 6 pieces for keyboard [from item 561]

"The Foliario Massbook." Collection of 16 anonymous polyphonic masses for 4, 5,6 , and 8 voices, compiled and copied by Francesco Foliario [from item 639]

Collection of 157 vaudevilles, chansons, amphigouris, couplets détachés, airs, etc., in French [from item 698]

The genre of the musical work is generally cited as part of the title entry. On balance, the accepted English form is used to maintain uniformity throughout the catalog, for example:

Offertory, Motet, Cavatina, Mass, Duet, Aria, Opera, Recitative, Singspiel, etc.

However, this is not a hard and fast rule; actual manuscript designations are used for genres of works whenever they seem inherently more descriptive and meaningful, for example:

Canzone militaire, Canzonetta francese, Ballo a solo, Romanza, Ottonari, etc.

In any case, the original form as it appears in the manuscript is given in full under the Inscription, or in the case of collections, under the Contents.

The compiler avoided assigning a musical genre to a composition when it did not appear in the inscription, except when the musical form was clearly evident, such as a recitative preceding an aria. For example, none of the "Tantum ergo's" in these vocal manuscripts are prefaced with generic names. Therefore, they have not been arbitrarily classed as "hymns," or "motets," or "prayers," and are thus omitted from Index IV: Musical Genres. (They are listed, however, in Index III: First Lines and Song Titles.)

\section{Collation}

Depending on conditions, eight distinguishing features are usually specified in the physical description: (1) the number and type of volumes; (2) the instrumentation and key; (3) the foliation or pagination including the preliminary leaves (p.l.) and end leaves (e.l.); (4) the format (upright or oblong); (5) the outer dimensions of the cover measured in centimeters (the vertical measurement is given first); (6) a succinct description of the binding (cover, spine, and edges); (7) a description of the watermark(s); and (8) the number of staves per leaf, for example: 
Printed libretto and MS score bound in 1 vol.: 2 p.l. + x, 48 pp. (libretto) +93 ff. (score) + 3 e.l.; upr.; $29.3 \times 22.8 \mathrm{~cm}$; cover: contemporary full leather with gilt-tooled spine; edges: trim. and dyed red; WM: J. SAUVADE FIN / AUVERGNE 1742; 12 stv. [from item 361]

The specific nomenclature of the instrumentation, for example, "for $S, A, T, B$, vln 1 2 , and org," is normally given in the physical collation, but it may occur under the Inscription or Contents, if these seem more appropriate, or to avoid repetition of information. Names of vocal and instrumental parts are given in English, except when it seems preferable to preserve the original manuscript designation, for example:

"2 colascioncini" [from item 550, no. 10]

The presence, absence, or occasional appearance of figures in the basso continuo (bc) parts are noted, because they may have a direct bearing on the musical style of the composition. This information is described as follows: "bc with figures," "bc without figures," "bc with sporadic figures," "realized bc," or "partially realized bc."

Many manuscripts came to the Berkeley Music Library lacking folio or page numbers. All were foliated (not paginated) by the compiler to facilitate study. If a manuscript was received with partial pagination, this system of numbers was continued to the end of the volume. With the exception of the Gregorian chant books and fragments, nearly all of the manuscripts described in this catalog are paper, so this material is not mentioned specifically. Manuscripts of parchment, or parchment and paper, are duly noted, for example:

Chant book: 2 p.l. +369 ff. (354 paper, 15 parchment) +1 e.l. [from item 654]

If the paper is moisture-stained, cropped, torn, etc., these conditions are recorded.

Some manuscripts, particularly commercial products, are enhanced with engraved decorative title page inscriptions and borders, and often bear the names of engravers, vendors, or other imprint data. These names are indexed.

Two terms used by the compiler to describe the covers need clarification. (1) When there is no preliminary leaf (p.l.) preceding, i.e., protecting, the first page of music, the term "no cover" is used. (2) The designation "staff paper" indicates that there is a preliminary leaf and that the material is made of ordinary music paper hand-ruled with staves. In either case the copyist normally prefaced the music with an inscription.

Italian manuscripts may contain fogli ("f.") numbers. Normally these were appended to the lower right-hand corner of the inscription leaf, and they tally the number of pages finished by the copyist. For example: f. $1=4$ pages; f. $1-1 / 4=5$ pages; f. 1 $1 / 2=6$ pages; f. $1-3 / 4=7$ pages; f. $2=8$ pages; f. $3=12$ pages; f. $3-1 / 4=13$ pages, etc. Factitious collections with multiple title leaves ordinarily contain several fogli numbers: item 572 (MS 112), for example, has seven. Abundant evidence in these manuscripts suggests the numbers were used to compute the cost of the copyist's labor and/or the vendor's sale price.

The compiler of this catalog was acutely aware of the technical complexities associated with the scientific classification, description, measurement, and evaluation of watermarks. His first instinct was to exclude them entirely from the catalog. Still, there was the nagging realization that watermarks are an inherent part of the physical document, and that the compiler had a responsibility to provide clues to what was actually present, and -equally important-what was not present. Consequently, an effort has been made 
to describe and index these graphic forms. (Incidentally, the manuscripts represented in this catalog provide a broad view of seventeenth and eighteenth-century Italian watermarks).

Some watermarks consist of single elements whose content can be described without much ambiguity, for example:

\section{WM: J. WHATMAN 1823, J. WHATMAN TURKEY MILLS 1826, S. BROOK} / 1824 [from item 625]

In cases where a watermark consists of two or more distinct graphic elements, of which the lowest one is a name or a group of letters, the description usually reads upwards. Here, the terms "beneath," "within," and "surmounted by" in the descriptive formula differentiate the graphic elements, for example:

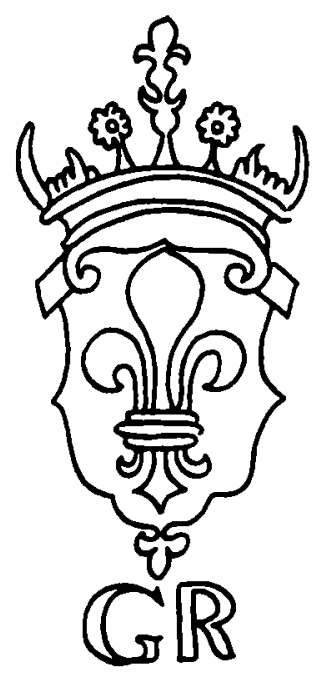

"GR beneath a fdl. within a shield surmounted by a crown" [from item 197]

When a name or group of letters is positioned above other graphic elements, the description usually reads downward, for example:

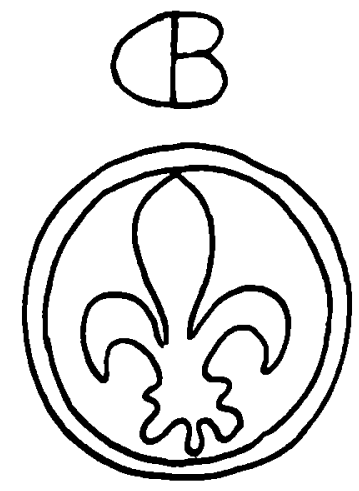

"CB atop a fdl. within dbl. circles" [from item 36] 
When a name or group of letters is positioned both above and below a centrallypositioned graphic design, the catalog description usually reads downward and the three distinct elements are separated by diagonal slashes, for example:

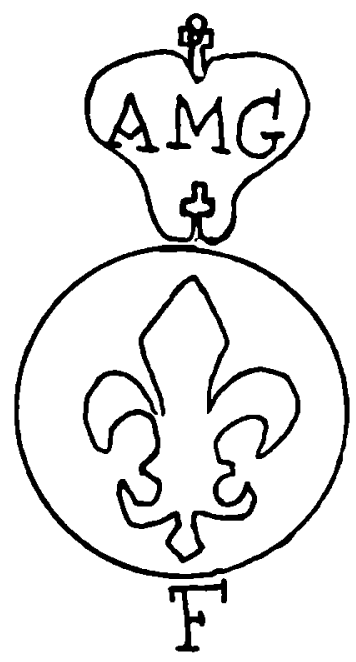

WM: AMG within a frame / fdl. within a sgl. circle / F [from item 100]

No attempt was made to describe the diverse styles of commonplace designs (such as fleur-de-lys), the size of the watermarks, the distance between chain lines, or to distinguish countermarks, etc. Virtually all the watermarks were mutilated when the original paper sheets were folded and cut to receive musical notation. Index $X$ is designed to provide access to these dispersed graphic elements; it is subdivided into six categories: dates; personal names, places, and descriptive words; letters and groups of letters; objects; armorial designs; and circles. (Special attention was paid to circles, because the compiler believes they are of critical importance to the classification of seventeenth- and eighteenth-century Italian watermarks.)

It goes without saying that watermarks are not always easy to read. It is possible the compiler misinterpreted some of the calligraphic elements because a descender or a loop was very faint. For example: he may have mistaken a " $C$ " for a " $G$," an " $F$ " for an "E," a "P" for a " $B$ ", an "O" for a "Q," etc.

\section{Provenance and Date}

Several approaches were used to establish the likely provenance and date of a manuscript. Occasionally the unusual specificity of local names of people, institutions, and dates that are preserved in the inscription seem to provide an indisputable place of origin, as, for example, the oratorio by Carlo Maria Colonnesi, $l l$ vaggio delle Marie al sepolcro, composed in $\mathbf{1 7 7 0}$ in the city of Velletri, near Rome:

Oratorio / o sia / Azzione Sagra per Musica / rappresentate / Il viaggio delle Marie al Sepolcro / Composto / Dal Nobil Uomo Carlo Maria Colonnesi Patrizio Veliteono I sotto la scuola, e direzzione del P: $\mathbf{M}^{\text {ro }}$. Giovanni Falasca Minor Conven-/tuale,

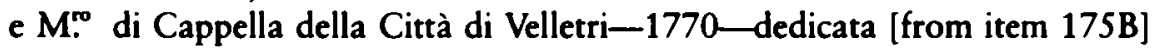


In the majority of cases, however, this essential information was based on indirect evidence. For example, item 536, a collection of 17 Italian arias, contains three place names (Vienna, Rome, and Naples), two dates (1750 and 1752), and the initials of the former owner "C. B. N." (Cavaliere Bartolomeo Nucci di Pescia). It is assumed, therefore, the manuscript of necessity must date after 1752, and that the place of origin is probably Pescia, rather than Vienna, Rome, or Naples, because it belongs to a group of manuscripts in the Berkeley Library that are associated with Nucci.

When it seemed impossible to infer a terminus a quo from internal documentary evidence or associations with other sources, then the style of music was used as the principal, if not risky, criterion. In such cases the opinions of others were sought. Apropos of this assistance, the compiler acknowledges with deep gratitude the suggestions offered by people whose names are cited in the Acknowledgments. The final responsibility for the reliability or unreliability of these dates and places, however, rests squarely with the compiler.

\section{Inscription}

Despite the vagaries of date, provenance, and authenticity posed by manuscript inscriptions, the original spellings, abbreviations, punctuation marks, and upper- and lower-case letters (or, lack thereof) are retained exactly, whenever possible. Diagonal slashes are used to mark the end of lines, secondary inscriptions are enclosed within quotation marks, and information introduced by the compiler is set apart in square brackets, for example:

Inscription (front cover): Mascarades. [Spine title] "Mascar / Du. R. De / Le Chine" [from item 354]

Names of owners frequently appear on the title page. More often than not the inscription is self-explanatory, for example:

“Di proprietà Di Anna Bernardini" [from item 200]

At other times the ownership statement can be determined readily from its position on the title page and/or a change of hand, for example:

[Added] "Piccirilli" [from item 249]

\section{Remarks}

Each manuscript has its own distinguishing characteristics-its unique personality, as it were. The purpose of this section is to alert the reader to special features and problems that are not covered adequately in other parts of the catalog description. Observations by others, which were solicited by the compiler, also appear here, for example:

Remarks: Robert Ford identified this as an autograph. Folio 8 is partly missing. These leaves were formerly ff. 179-86 of another MS [from item 431]

\section{Inventory of Contents}

The contents of manuscripts are unpredictable, and the occurrence of various types of music may be characteristically homogeneous or quite random. Frequently these distinctions are blurred by physical peculiarities: the presence of several scribal hands, 
